\title{
O CAPITAL AGRÍCOLA E AS NOVAS ESPACIALIDADES GERADAS: Araguari/Minas Gerais
}

\author{
the agricultural capital and the new spatiality generated: Araguari/MG
}

\author{
Flávia Aparecida Vieira de Araújo* \\ Beatriz Ribeiro Soares**
}

\begin{abstract}
Resumo
O objetivo central deste artigo constitui-se na análise das novas espacialidades geradas na área urbana de Araguari/MG pela inserção do capital agrícola no município. Essas são aqui entendidas como o aparecimento de novos estabelecimentos comerciais e de serviços que surgem para atender às necessidades do campo modernizado, ligados aos ramos de atividades econômicas que são representativas da atuação dos novos agentes econômicos. Esses trazem novas práticas e formas de atuação, e expressam a incorporação do território brasileiro ao capitalismo contemporâneo. Nessa perspectiva, as variáveis selecionadas para a análise foram: lojas de revenda de adubos, sementes e fertilizantes; e de tratores, peças e serviços. A importância da pesquisa justifica-se pelo fato de que o levantamento desses equipamentos leva ao entendimento da organização espacial intraurbana. Essa possibilita compreender o conteúdo, a funcionalidade e a dinâmica de determinado núcleo urbano. A pesquisa possibilitou verificar que o processo de modernização agrícola em Araguari não ficou restrito ao campo, pois imprimiu uma nova organização à cidade, verificada pela ampliação dos fixos.
\end{abstract}

Palavras-chave: Modernização agrícola, Espacialidades, Araguari/MG.

\begin{abstract}
The aim of this paper is the analysis of new spatialities generated in the urban area of Araguari/MG by the insertion of agricultural capital in the city. These are understood here as the emergence of new shops and services that appear to meet the needs of the modernized country, connected to the branches of economic activities that are representative of the performance of new economic agents. They bring new practices and forms of action, and express the inclusion of Brazil in the contemporary capitalism. From this perspective, the variables selected for analysis were: stores of fertilizers, seeds, tractors, auto parts and services. The importance of the research is justified by the fact that the research of such urban equipments turns into the understanding of the intra-urban spatial organization. This makes it possible to understand the content, function and dynamics of a given urban area. The research enabled us to verify that the process of agricultural modernization in Araguari was not restricted to the field, since printed a new organization to the city, checked by the expansion of the sets.
\end{abstract}

Key words:Agricultural modernization, Spaciliaties, Araguari/MG.

\section{Résumé}

L'objectif central de cet article constitue dans l'analyse des nouveaux espaces généré sur l'aire urbaine de Araguari/MG par l'insertion du capital agricole au municipe. Celles-ci sont comprises comme l'apparition des nouveaux établissements comerciaux et de services qui apparaîssent pour atteindre les besoins de la campagne moderniseé, rapportés à ramifications des activités économiques qui sont representatives de la performance des nouveaux agents économiques. Ceux-ci apportent des nouvelles pratiques et formes de performance, et extériorisent l'incorporation du territoire brésilien au capitalisme contemporain. Dans cette perspective, les variables choisies pour l'analyse sont : magasins de reventes d'engrais, sements et fertilisants; et de tracteurs, pièces et services. L'importance de la recherche est justifiable à cause de que le soulèvement de ces équipaments apporte à la compréhension de l'organisation de l'espace « intraurbana ». Cette possibilité comprend le contenu, le fonctionnement et la dinamique de determiné coeur urbaine. La recherche a possibilité vérifier que le procès de la modernisation agricole à Araguari n'a pas été restreint à la campagne, car il a imprimé une nouvelle organisation à la ville, verifié par l'élargissement des figés.

Mots-clés:Modernisation agricole, Espaces, Araguari/MG.

(*) Mestre pelo Programa de Pós-Graduação em Geografia da Universidade Federal de Uberlândia - Campus Santa Mônica, Bloco 1H; Av. João Naves de Ávila, 2121 - CEP: 38400-902, Uberlândia (MG) - Brasil, Tel/Fax: (+ 55 34) $32394169 / 32394221$ - flaviaraujogeo@yahoo.com.br

(**) Prof ${ }^{a}$. Dra . do Instituto de Geografia da Universidade Federal de Uberlândia - Av. João Naves de Ávila, s.n, Bl H, Santa Mônica, CEP: 38.400-902, - Uberlandia (MG) - Brasil, Tel/Fax: (+55 34) 32394169 / 32394210 - brsoares@ufu.br 


\section{INTRODUÇÃO}

O avanço e o crescimento da agricultura no cerrado foram determinados pelo progresso técnico possibilitado pela pesquisa e experimentação, e pelos incentivos governamentais, os quais se consubstanciaram em programas regionais de desenvolvimento agrícola. Tais programas foram responsáveis pelo fornecimento de crédito subsidiado, que viabilizou a mecanização agrícola e, mais do que isso, a tecnificação do campo, ou seja, a maior presença da técnica e da ciência no processo produtivo rural e, consequentemente, nas relações socioespaciais, caracterizando o meio técnico-científico-informacional, do qual nos fala Santos (1993).

Não obstante os benefícios advindos dos programas agrícolas, deve-se considerar que eles foram estendidos a uma reduzida parcela da população, sendo destinados a produtores, propriedades, produtos e regiões específicas, o que é apontado por Pessôa e Cavalini (1988). Tal fato levou diversos estudiosos, como Graziano da Silva (1982), a denominar a inserção de modernas técnicas no campo, no período compreendido entre os anos de 1965 e 1979, como a "modernização conservadora".

Nesse contexto, as políticas agrícolas no município de Araguari, localizado em área de cerrado, também se dirigiram ao financiamento do cultivo de produtos destinados a abastecer o mercado externo, principalmente o café e, mais tarde, a soja.

A inserção do município de Araguari em um contexto mais amplo de modernização da agricultura brasileira não foi diferente do que ocorreu nas áreas de cerrado, nas quais houve uma ruptura gradual da autossuficiência das áreas rurais, que passaram a funcionar segundo os ditames do capitalismo e estabelecer relações interdependentes com os setores industrial, comercial e de serviços.

A incorporação de ciência, técnica e informação ao campo mudou sua dinâmica, ao intensificar o uso de sementes especializadas e de insumos e fertilizantes para a correção e fertilização do solo, o que é apontado por Santos (1997). O autor afirma que a ciência, a tecnologia e a informação passam a integrar as tarefas cotidianas do campo modernizado. E, dessa maneira, o solo passa a ser corrigido e fertilizado, as plantas são protegidas pelos inseticidas e um novo calendário agrícola é imposto. Tal imposição ocorre graças à informação, e, a partir disso, as cidades médias do interior passam a contar com um "coeficiente de modernidade" (SANTOS, 1997, p. 45).

O coeficiente de modernidade apontado pelo autor deve-se ao fato de que as cidades passaram $\mathrm{a}$ atender às exigências do campo modernizado e a regularem a dinâmica desse espaço. $\mathrm{E}$, nesse contexto, novas espacialidades foram geradas nas áreas urbanas.

Nessa perspectiva, o objetivo central desse trabalho é a análise das novas espacialidades geradas na área urbana de Araguari pela inserção do capital agrícola no município. É importante destacar que essas se referem ao aparecimento de novos estabelecimentos comerciais e de serviços que surgem para atender às necessidades do campo modernizado, como lojas de revenda de adubos, sementes e fertilizantes; e de tratores, peças e serviços.

Para o levantamento dos equipamentos selecionados para a pesquisa, o recorte temporal abarcou o período de 1999 a 2009, sendo isso justificado pelo fato de que se pretendeu compreender a dinâmica da cidade de Araguari após a intensificação do processo de modernização agrícola. A partir da década de 1970, esse processo imprimiu transformações significativas no território brasileiro e redefiniu o papel das cidades. Em Araguari, foi apenas na década seguinte (1980) que esse processo efetivamente se consolidou, com o cultivo do café, no primeiro momento, e, posteriormente, de maracujá e tomate.

O levantamento foi realizado em listas telefônicas da cidade referentes aos anos de 1999 e de 2009. Todavia para este último ano, aliado à consulta ao guia telefônico, entendeu-se a necessidade da realização de trabalhos de campo, os quais permitiram a elaboração de mapas.

Para uma melhor organização do trabalho, ele foi estruturado em duas partes, além das considerações finais. As considerações acerca das novas espacialidades geradas pela inserção do capital agrícola em Araguari são discutidas na primeira parte, sendo que na segunda é realizada uma análise mais detalhada sobre os fixos selecionados para análise. 


\section{O CAPITAL AGRÍCOLA E AS NOVAS ESPACIALIDADES GERADAS}

Antes de nos atermos à discussão proposta, consideramos necessário apresentar a localização de Araguari. O município de Araguari localiza-se na porção norte da mesorregião do Triângulo Mineiro/Alto Paranaíba, no estado de Minas Gerais, possuindo como áreas limítrofes os municípios de Uberlândia, Tupaciguara, Cascalho Rico, Estrela do Sul e Indianópolis (figura 1). A área total do município é de $2.730 \mathrm{Km}^{2}$, sendo $2.675 \mathrm{Km} 2$ de área rural e $55 \mathrm{Km}^{2}$ de área urbana, e está dividida em cinco distritos, sendo eles: Araguari (distrito-sede), Amanhece, Florestina, Piracaíba e Santo Antônio/Contenda.

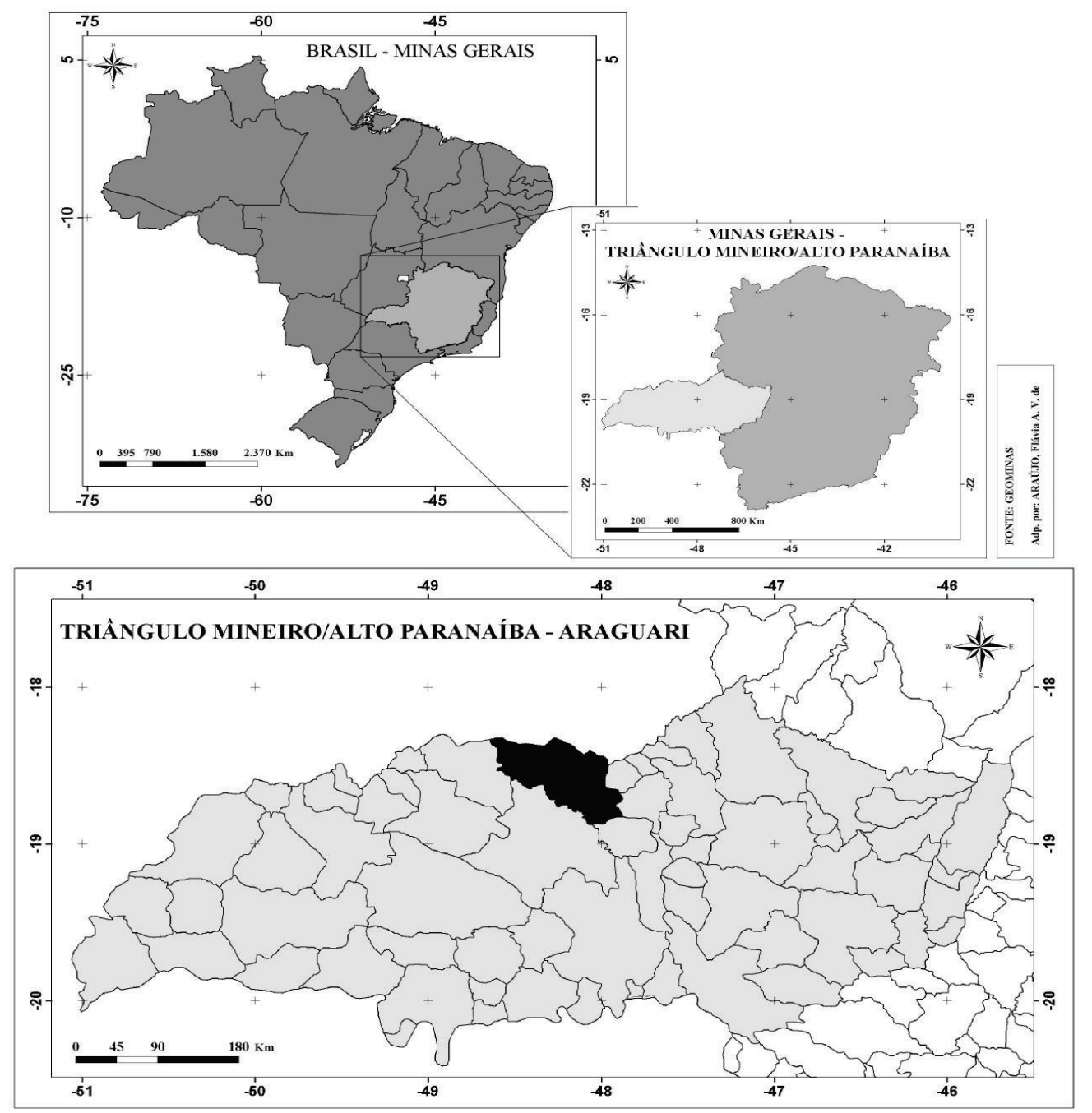

Figura 1 - Araguari (MG): localização do município (2011)

Fonte: http://www.geominas.mg.gov.br/ Adaptado por: ARAÚJO, F. A. V. (2011)

Um importante aspecto que se observa no contexto da modernização agrícola do país e, especificamente, no município de Araguari é a nova configuração das cidades, que passam a atender às exigências do campo modernizado, implantando lojas de insumos e fertilizantes agrícolas, tornando-se, assim, o lugar da regulação da dinâmica do campo. Conforme aponta Santos (1993, p. 52), a cidade passa a regular as atividades realizadas no campo. Dessa maneira, assegura a cooperação que a nova divisão do trabalho agrícola impõe. $\mathrm{O}$ autor destaca que a cidade atende às exigências do campo e responde às suas demandas cada vez mais urgentes, ou seja, as respostas são, consideravelmente, mais rápidas. 
Ainda de acordo com Santos (1997, p. 94), é a partir da cidade que se pode planejar grande parte das atividades presentes no campo e na própria cidade. É nela que se pode regular a atividade agrícola e se identificar as rápidas mudanças às quais o campo se subordina, devido às imposições do processo de globalização.

A nosso ver, é importante destacar também as ideias de Elias (2007). De acordo com a autora, a partir da produção agrícola e agroindustrial intensiva, há uma exigência por parte do campo para que as cidades se adaptem e atendam às suas principais demandas. As cidades se convertem, assim, no principal laboratório do campo, pois são responsáveis pelo fornecimento da maior parte dos "aportes técnicos, financeiros, jurídicos, de mão-obra e de todos os demais produtos e serviços necessários à sua realização" (ELIAS, 2007, p. 118). A autora aponta ainda que quanto maior a modernidade presente nessas atividades, maior o caráter urbano de sua regulação.

De acordo com as ideias dos dois autores supracitados, a presença de ciência, de técnica e de informação nos objetos geográficos presentes no campo engendra transformações socioespaciais não apenas nesse espaço, mas também, e principalmente, nas cidades. Essas, frente à necessidade de atenderem à crescente demanda imposta pelas áreas rurais modernizadas, têm sua organização espacial intraurbana modificada. A exigência por profissionais qualificados é cada vez maior, o que contribui para um redimensionamento do conteúdo, do papel e das funções urbanas. Os fatores econômicos deixam de ser negligenciados e, juntamente com os aspectos sociais, tornam-se determinantes para esse redimensionamento.

Nesse sentido, Santos (1993, p. 51) nos aponta que há uma mudança de conteúdo nas cidades. Se, antes, eram consideradas as "cidades dos notáveis", hoje, devido às transformações, podem ser classificadas como as "cidades econômicas". Na "cidade dos notáveis", o padre, o tabelião, a professora primária, o juiz, o promotor e o telegrafista eram as personalidades que possuíam maior notoriedade. $\mathrm{Na}$ "cidade econômica", os profissionais que adquirem importância são: agrônomo (que, até então, vivia nas capitais), veterinário, bancário, piloto agrícola, especialista em adubos e aquele que é responsável pelos comércios especializados.

Santos (1993) aponta que o processo de regulação do campo pela cidade está ligado ao aumento do consumo produtivo e não apenas consuntivo. Dessa forma, nos esclarece que à medida que ocorre a modernização do campo, por meio da inserção de máquinas, implementos, componentes, insumos materiais e intelectuais necessários à produção, à administração pública e privada e ao crédito, há uma mudança no mecanismo (que se expressa no território) relativo à oferta e demanda de serviços. Em uma etapa anterior, o consumo existente nas áreas rurais e mesmo nas cidades restringia-se a um consumo consuntivo. Quanto maiores os excedentes disponíveis, maior era a expressividade deste. A partir do processo de modernização agrícola, há um crescimento do consumo produtivo, o qual passa a representar uma significativa parcela das trocas realizadas entre os locais da produção agrícola e os núcleos urbanos.

O consumo produtivo rural não se adapta às cidades, mas, ao contrário, as adapta. Estas são chamadas a dar respostas particulares às necessidades das produções particulares, e daí a maior diferenciação entre as cidades. Estas se diferenciam cada vez mais pelo fato de o nexo do consumo produtivo ser ligado à necessidade de encontrar, no lugar e na hora, respostas indispensáveis à marcha da produção. Este fenômeno, antes restrito às cidades, que eram "depósitos" para os fatores da produção industrial, agora também se dá no campo, com a diferença de que, a partir desse momento, a regulação do mundo rural não se faz mais no campo. Hoje, nas áreas mais desenvolvidas, todos os dados da regulação agrícola se fazem no urbano, novidade que em muito muda a significação, neste período, da urbanização brasileira (SANTOS, 1993, p. 56). 
A redefinição do consumo do campo decorrente do processo de modernização agrícola é também discutida por Elias (2007), ao apontar que: "A modernização da atividade agrícola e agroindustrial, em especial, redefine o consumo do campo, que deixou de ser apenas consumptivo para se tornar cada vez mais produtivo, e criou demandas até então inexistentes" (ELIAS, 2007, p. 120).

$\mathrm{O}$ crescimento do consumo produtivo rural, associado à migração resultante da modernização agrícola, condiciona uma reestruturação econômica e espacial, a qual pode ser percebida por um incremento da urbanização, que se torna, assim, mais dinâmica e complexa.

Dessa maneira, deve-se levar em conta que dentre os diversos fatores que influenciam o processo de reorganização do território brasileiro, a dinâmica estabelecida pela moderna produção agropecuária possui importante parcela de contribuição, o que é corroborado nas seguintes palavras de Elias (2007, p. 114):

Não são poucas as evidências de que a dinâmica da produção agropecuária globalizada é um dos vetores da reorganização produtiva do território brasileiro. Em todas as áreas nas quais se verifica a difusão do agronegócio, processa-se uma reestruturação da economia e do espaço, resultando no incremento da urbanização, especialmente associado ao crescimento do consumo produtivo, da migração e do mercado de trabalho.

A autora prossegue afirmando que, no Brasil, o processo acelerado de urbanização é um dos reflexos da reestruturação produtiva da agropecuária. O crescimento urbano é decorrente das novas relações estabelecidas entre o campo e a cidade. Tais relações foram impulsionadas pelas necessidades do consumo produtivo agrícola. Esse, conforme nos aponta a autora, possui um crescimento mais rápido do que o "consumo consumptivo" (ELIAS, 2007, p. 117).

O aumento do consumo produtivo agrícola, discutido pela autora, também pode ser observado em Araguari a partir do aparecimento de novos estabelecimentos comerciais que surgiram para atender às necessidades do campo modernizado, como loja de venda de insumos, fertilizantes e máquinas agrícolas, o que contribuiu para uma nova configuração espacial urbana, conforme será discutido a seguir.

Deve-se lembrar que o aumento desse consumo diz respeito ao processo de terceirização, o qual está relacionado à ampliação de bens e serviços e, de forma específica, às exigências do campo modernizado, ou seja, a compra de produtos ligados às próprias atividades agropecuárias: insumos, fertilizantes e maquinários.

$\mathrm{Na}$ perspectiva de analisar a importância do setor agropecuário no cenário econômico do município de Araguari, julgamos importante elencar os setores econômicos mais representativos de ocupação da população do município, o que é demonstrado na tabela 1.

$\mathrm{Na}$ tabela 1 é possível perceber que no ano 2000, a maior representatividade foi do setor de serviços, responsável pela ocupação de 18.820 pessoas, o que equivale a $42,8 \%$ do total. O setor industrial ficou na segunda posição, com $21,7 \%$ do total, o que corresponde a 9.558 pessoas. $\mathrm{O}$ comércio de mercadorias foi responsável pela ocupação de 7.900 pessoas, representando, assim, $18,0 \%$ do total. O setor primário foi o que menos ocupou, envolvendo 7.700 pessoas, o que representa $17,5 \%$ do total.

Ao se comparar a população rural do município de Araguari no ano 2000 (9.226 habitantes) com o número de trabalhadores empregados em atividades agropecuárias nesse mesmo período (7.700 pessoas) nota-se que é menor. Constata-se que, do total populacional residente na área rural, $83,5 \%$ estavam empregados em atividades agropecuárias, de extração vegetal e pesca. A nosso ver, essa diferença pode estar ligada à mecanização do campo, que eliminou postos de trabalho no meio rural, levando a população desse espaço a procurar emprego na área urbana do município. 
ARAÚJO, F. A. V.; SOARES, B. R.

Tabela 1- Araguari (MG): população ocupada por setores econômicos (2000)

\begin{tabular}{l|c}
\hline SETORES & NÚMERO DE PESSOAS - 2000 \\
\hline Agropecuária, extração vegetal e pesca & 7.700 \\
\hline Industrial* & 9.558 \\
\hline Comércio de mercadorias & 7.900 \\
\hline Serviços** & 18.820 \\
\hline Total & $\mathbf{4 3 . 9 7 8}$ \\
\hline
\end{tabular}

Notas da tabela: *Estão incluídas: indústria de transformação, construção e outras atividades industriais. **Estão incluídos: prestação de serviços, social, administração pública, serviços auxiliares de atividades econômicas e outras atividades mal especificadas.

Fonte: IPEADATA - Censo Demográfico (2000)

Org.: ARAÚJO, F. A. V. (2011)

Ao se estabelecer uma comparação entre a população ocupada por setores econômicos (tabela 1) com a PEA - população economicamente ativa- e a população ocupada por área de residência (tabela 2), é possível notar que, no ano 2000, a PEA rural representava 56,5\% do total de pessoas ocupadas no setor primário. E em relação à população ocupada nessa área, a representatividade era de $55,3 \%$ do total de ocupados no setor primário.

Tabela 2 - Araguari (MG): população economicamente ativa e população ocupada por área de residência (1970-2000)

\begin{tabular}{c|c|c|c|c|c|c|c|c}
\hline \multirow{2}{*}{ POPULAÇÃO } & \multicolumn{2}{|c|}{ POPULAÇÃO ECONOMICAMENTE ATIVA } & \multicolumn{4}{|c}{ POPULAÇÃO OCUPADA* } \\
\cline { 2 - 10 } & 1970 & 1980 & 1991 & 2000 & 1970 & 1980 & 1991 & 2000 \\
\hline Total & 19.571 & 32.781 & 39.908 & 50.329 & 18.840 & 32.232 & 38.820 & 43.978 \\
\hline Urbana & 15.281 & 28.899 & 36.163 & 45.972 & 14.592 & 28.357 & 35.095 & 39.718 \\
\hline Rural & 4.290 & 3.882 & 3.745 & 4.357 & 4.248 & 3.875 & 3.724 & 4.260 \\
\hline
\end{tabular}

Fonte: IPEADATA - Censos Demográficos: 1970, 1980, 1991 e 2000

Nota da tabela: * Foi considerada como ocupada a pessoa que trabalhou nos últimos 12 meses anteriores à data de referência do Censo, ou parte deles. A pessoa que não trabalhou nos últimos 12 meses anteriores à data de referência do Censo, mas que, nos últimos dois meses tomou alguma providência para encontrar trabalho, foi considerada como desocupada Org.: ARAÚJO, F. A. V. (2011)

De acordo com o que foi discutido a partir dos dados contidos nas tabelas 1 e 2, verifica-se que as atividades urbanas são aquelas de maior expressividade quanto à ocupação das pessoas residentes no município. E ao analisarmos essas atividades de forma mais específica, nota-se que correspondem tanto ao setor secundário quanto terciário da economia (tabela 1).

A análise do PIB (Produto Interno Bruto) gerado pelas atividades de serviços possibilita observar que entre os anos de 1999 e 2003, esse setor era o mais representativo em relação ao valor total do PIB de Araguari, apresentando, nesse período, o maior percentual no ano de 2001 (44,0\%) e o menor no ano 2000 (41,0\%) em relação às demais atividades econômicas (tabela 3).

No período compreendido entre os anos de 2004 e 2007, nota-se que a maior representação no valor total do PIB foi do setor industrial, variando entre 47,5\% (percentual apresentado no ano de 2006) e 39,8\% (percentual relativo ao ano de 2004). 
Tabela 3 - Araguari (MG): PIB a preços correntes de mercado, em R\$, por setores de atividade econômica (1999-2007)

\begin{tabular}{c|c|c|c|c|c}
\hline ANO & AGROPECUÁRIA & INDÚSTRIA & SERVIÇOS & OUTROS* $^{*}$ & TOTAL \\
\hline $\mathbf{1 9 9 9}$ & 95.388 & 182.279 & 300.817 & 111.766 & 690.250 \\
\hline $\mathbf{2 0 0 0}$ & 119.432 & 211.449 & 315.965 & 122.890 & 769.736 \\
\hline $\mathbf{2 0 0 1}$ & 117.424 & 203.234 & 364.092 & 141.079 & 825.829 \\
\hline $\mathbf{2 0 0 2}$ & 165.969 & 233.806 & 407.400 & 156.763 & 963.938 \\
\hline $\mathbf{2 0 0 3}$ & 136.099 & 377.135 & 422.129 & 166.759 & 1.102 .122 \\
\hline $\mathbf{2 0 0 4}$ & 152.784 & 567.288 & 511.993 & 192.375 & 1.424 .440 \\
\hline $\mathbf{2 0 0 5}$ & 157.313 & 713.485 & 564.274 & 224.858 & 1.659 .930 \\
\hline $\mathbf{2 0 0 6}$ & 144.190 & 858.538 & 568.904 & 233.068 & 1.804 .700 \\
\hline $\mathbf{2 0 0 7}$ & 148.495 & 916.668 & 652.024 & 259.533 & 1.976 .720 \\
\hline
\end{tabular}

Fonte: FJP (2007)

Nota da tabela: *Inclui administração pública e impostos Org.: ARAÚJO, F. A. V. (2011)

Não obstante a menor representatividade de participação do setor agropecuário no PIB total no período de 1999 a 2007, é válido ressaltar que, em função da maior interligação entre os três setores da economia, decorrente do processo de modernização agrícola, diversas atividades que são classificadas como sendo características dos setores industrial e de serviços, estão ligadas, ainda que de forma indireta, ao setor agropecuário.

Desse modo, diversos serviços urbanos estão ligados às atividades agropecuárias, constituindo-se em novas espacialidades que foram geradas pela modernização do campo a partir da instalação de fixos, como será discutido a seguir.

\section{AS NOVAS ESPACIALIDADES EM ARAGUARI/MG: uma análise dos fixos}

Na perspectiva de se discutir sobre as novas espacialidades geradas pela inserção do capital agrícola no município de Araguari, consideramos a importância da análise da dinâmica de expansão das lojas de revenda de adubos e fertilizantes; e de tratores, peças e serviços. Dessa maneira, foram levantados e mapeados os estabelecimentos existentes na cidade, nos anos de 1999 e 2009, conforme ilustram as figuras 2 e 3 .

Como pode ser verificado na figura 2, nota-se uma descentralização dos estabelecimentos comerciais de revenda de adubos, sementes e fertilizantes. Verifica-se que antes eram mais restritos à área central, sendo que nos últimos anos houve uma maior dispersão desses para áreas mais periféricas do espaço urbano. Esse novo caráter de distribuição espacial pode ser explicado, dentre outros fatores, pelo aumento dos custos de terrenos no setor central da cidade. Frente à necessidade de ampliação do prédio para abrigar o maior estoque de produtos e de estacionamentos mais amplos para os clientes, a permanência na área central é inviabilizada, o que leva à dispersão das unidades para bairros mais afastados dessa área.

Todavia, esse deslocamento não representa uma mudança de endereço casual, visto que os estabelecimentos passam a se localizar estrategicamente nas importantes vias de circulação da cidade, ou seja, nas principais avenidas, que permitem maior acessibilidade aos consumidores dos produtos revendidos nessas lojas.

No que tange aos estabelecimentos comerciais de revenda de tratores, peças e serviços, nota-se que, no período que compreende os anos de 1999 e 2009, não houve alterações em relação ao número, visto que houve a permanência de cinco estabelecimentos (figura 3). 


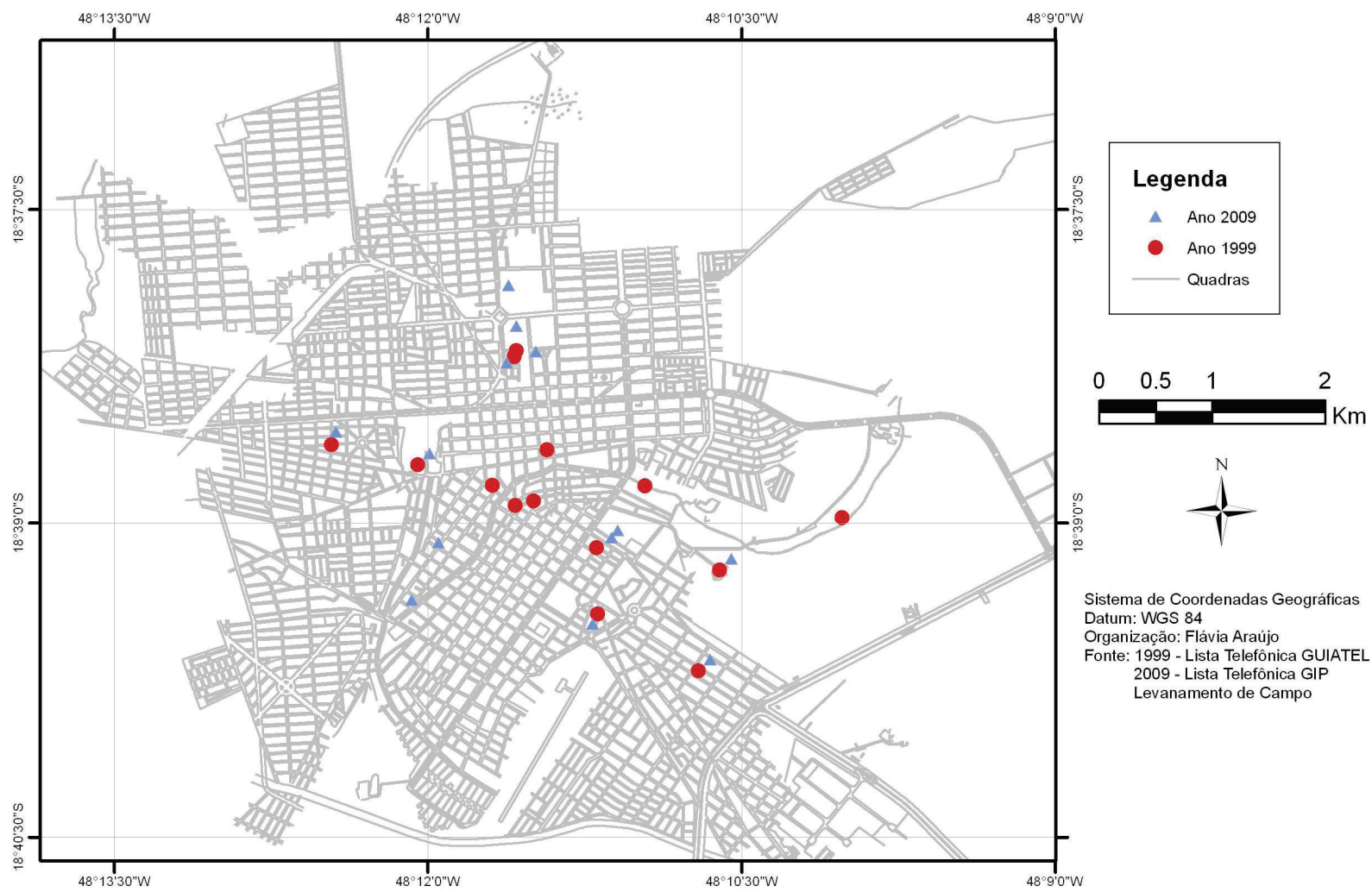

Figura 2 - Araguari (MG): estabelecimentos comerciais de revenda de adubos, sementes e fertilizantes (1999-2009)
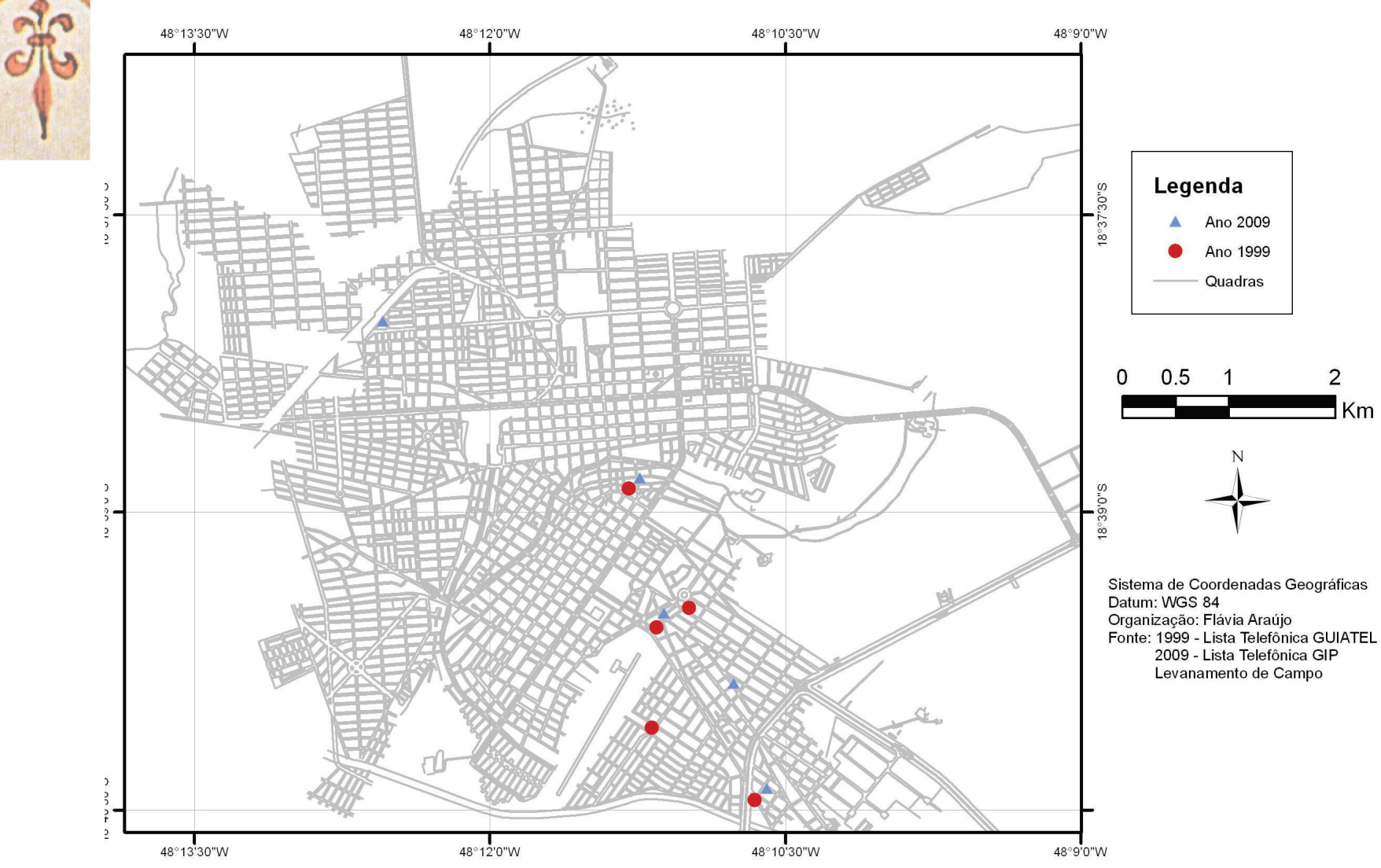

Figura 3 - Araguari (MG): estabelecimentos comerciais de revenda de tratores, peças e serviços (1999-2009) 
É importante ressaltar que a utilização de máquinas agrícolas na colheita das lavouras se tornou cada vez mais frequente e isso pode ser evidenciado a partir da evolução do número de tratores do município. De acordo com dados do Censo Agropecuário, no período de 1970 a 1995, esse número passou de 64 para 1075 máquinas, representando um crescimento superior a 15 vezes (IBGE, 1970; 1995). Destarte, verifica-se que o município de Araguari também vivenciou o processo de mecanização do campo, sendo, portanto, um reflexo do processo de modernização agrícola ocorrido nas áreas de cerrado.

\section{CONSIDERAÇÕES FINAIS}

A pesquisa possibilitou observar que o processo de modernização da agricultura no município de Araguari também atendeu aos interesses das políticas desenvolvimentistas que visavam ao aumento da produção e produtividade. Tal processo levou à expansão da mancha urbana, em função da migração resultante. A mecanização do campo, ao condicionar mudanças nas relações de trabalho e contribuir para o aparecimento de novas formas de exploração agrícola, fez emergir um considerável contingente populacional que migrou do campo em direção à cidade, aumentando, assim, os fluxos entre essas duas áreas.

Assim, a modernização agrícola aumentou a relação campo-cidade, ao mesmo tempo em que intensificou o aumento do consumo produtivo agrícola, o que demandou novos estabelecimentos comerciais e de serviços, condicionando, uma nova dinâmica ao desenvolvimento urbano da cidade.

Nessa perspectiva, conclui-se que o processo de modernização agrícola em Araguari não ficou restrito ao campo, pois imprimiu uma nova organização à cidade, a qual pode ser visualizada em seu espaço intraurbano. $\mathrm{O}$ crescimento, diversificação e complexificação dos equipamentos, aqui entendidos como fixos, determinaram uma nova dimensão às interações socioespaciais estabelecidas pela cidade. Destarte, aponta-se a necessidade da realização de novas pesquisas que analisem os fluxos da cidade de Araguari, na medida em que a análise dos fixos e dos fluxos possibilita compreender de forma efetiva o conteúdo, a funcionalidade e a dinâmica de determinado núcleo urbano.

\section{AGRADECIMENTOS}

A metodologia utilizada nesta pesquisa está baseada no trabalho desenvolvido pela ReCiMe (Rede de Pesquisadores sobre Cidades Médias), que reúne pesquisadores do Brasil, Argentina e Chile. No Brasil, essa rede conta com participação de pesquisadores de diversas universidades, dentre as quais se encontra a UFU.

\section{REFERÊNCIA BIBLIOGRÁFICA}

ELIAS, Denise. Agricultura e produção de espaços urbanos não metropolitanos: notas teórico-metodológicas. In: SPOSITO, Maria Encarnação Beltrão (Org.). Cidades médias: espaços em transição. São Paulo: Expressão Popular, 2007. p. 113-138.

FUNDAÇÃO JOÃO PINHEIRO (FJP). PIB 1999 a 2007. [s.n.t.].

GRAZIANO DA SILVA, José. A modernização dolorosa: estrutura agrária, fronteira agrícola e trabalhadores rurais no Brasil. Rio de Janeiro: Zahar, 1982. 192 p.

IPEADATA. Dados estatísticos do município de Araguari. Disponível em <http://www.ipeadata.gov.br>. Acesso em: 21 fev. 2011.

PESSÔA, Vera Lúcia Salazar; CAVALINI, Maria Benedita. O espaço rural no Triângulo Mineiro: principais transformações nas últimas décadas. Cadernos de Geografia, Uberlândia, AGB: 1988. p. 1-20.

SANTOS, Milton. A urbanização brasileira. São Paulo: Hucitec, 1993. 157 p. 
SANTOS, Milton. Técnica, espaço, tempo: globalização e meio técnico-científico-informacional. 3. ed. São Paulo: Hucitec, 1997. 190 p.

SPOSITO, Maria Encarnação Beltrão et al. O estudo das cidades médias brasileiras. In: SPOSITO, Maria Encarnação Beltrão (Org.). Cidades médias: espaços em transição. São Paulo: Expressão Popular, 2007. p. 35-67.

Trabalho enviado em outubro de 2011

Trabalho aceito em novembro de 2011 